\title{
OPTIMIZATION USING RESPONSE SURFACE METHODOLOGY AND ARTIFICIAL NEURAL NETWORK IN GEARED DRILLING
}

\author{
Yegireddi Shireesha $^{1,2}$, Nandipati Govind ${ }^{3}$ \\ ${ }^{1}$ Department of Mechanical Engineering, Acharya Nagarjuna University, Guntur, India \\ ${ }^{2}$ Department of Mechanical Engineering, GMR Institute of Technology, Rajam, India \\ ${ }^{3}$ Department of Mechanical Engineering, R.V.R \& J.C College of Engineering, India
}

Corresponding author: Y.Shireesha, y.shireesha@gmrit.edu.in

\begin{abstract}
Drill on different layered composite causes to force the layers ahead of it, creating unacceptable delamination on the leaving side. The current work describes the influence of different process parameters like spindle speed, feed, diameter of drill bit and addition of filler material on delamination damage on carbon and jute hybrid fiber composites during drilling operation. The experimental output for delamination is optimized by RSM-Response Surface Methodology and ANN-Artificial Neural Network Model. The experimental prediction model was established by considering DOE (design of experiments) of three levels performed with drilling operation by varying above said process parameters The optimum values for minimized delamination damage conditions found to be at (J-C-C-J) $+5 \mathrm{~g}$ of filler (fly-ash) composite. This is drilled with $8.5 \mathrm{~mm}$ diameter drill bit with a feed of $0.08 \mathrm{~mm} / \mathrm{rev}$ at $875 \mathrm{rpm}$ speed. From the theoretical results it is recognized that cutting-speed and filler-material have much influencing factors on responses (delamination), and their individual contribution in an order of $47.25 \%$ and $47.32 \%$ respectively. By using Box-Behnken design RSM model is developed, with a feed-forward back-propagation method to develop the predictive ANN model which consists of 15 neurons in its hidden layer along with ANN Model. Here ANN Results $\left(\mathrm{R}^{2}=0.99\right.$ and $\left.\mathrm{RMSE}=1.99\right)$ showed that the developed model is performing better to predict content of delamination when compare to RSM results $\left(\mathrm{R}^{2}=0.97\right.$ and RMSE=2.24).
\end{abstract}

Key words: carbon-jute hybridization, delamination, filler material, Response surface methodology, Artificial Neural Network.

\section{INTRODUCTION}

Hybrid composite material is the synthesis of two or more fiber materials which are mixed and bonded together. Generally, a composite material consists of matrix (epoxy, polyester, polypropylene etc.) and the reinforcement (natural or synthetic fibers) [1]. The matrix transfers load to the fibers and it also protects the reinforcement from the environment. The matrix binds the reinforcement together and the reinforcement improves the properties of the composite materials. Due to the advantages of natural fibers nowadays these are becoming more popular in many areas. Due to the advantages of natural fibers they have a capability to replace the man-made or synthetic fibers. These natural fibers are cheaper than the synthetic fibers. They are biodegradable, recyclable, renewable and eco-friendly. Other advantages of natural fibers are low density, less weight and less cost [1]. The advantage of hybrid composites is that it possesses high strength while compared to other composites [2]. Due to the attractive and efficient properties, polymer based systems having greater significance are used in all fields. Different approaches were introduced to compare the material properties of hybrid fiber composites with conventional materials. For identifying the fiber composite delamination characteristics material is transferred for drilling test. Many researchers were conducted delamination process to know the fracture behavior of different combinations of fiber reinforced composites [1-5]. To know the fracture behavior of Jute-sisal glass reinforced polyester hybrid composites, drilling test is carried at different spindle speeds and different drill diameters by altering the feed rates. And observed that delamination factor is in proportion with feed and dill diameter whereas inversely proportion to spindle speed. Author suggested that drilling at low feed rate and high spindle speed is suitable for jute-sisal-glass reinforced hybrid composites [3]. Similarly, mono fiber with different filler material is considered to identifying the effect of filler on delamination with spindle speed and feed [4]. Here Silicon carbide and zinc oxide were two materials used as the filler materials. With increase in the cutting speed the delamination factor decreased and by increasing feed rate the delamination factor increased for zinc-oxide filler material. In addition to the aspects presented above authors concentrated on different types of drill bits to understand the delamination process. For this experimentation high speed steels (HSS) and carbide twist drill bits were used during the drilling. The optimal conditions for thrust force and delamination factor when drilling basalt/sisal fibre composites were found by ANOVA analysis. The results showed $3 \mathrm{~mm}$ 
diameter HSS tool with a feed and speed of $0.1 \mathrm{~mm} / \mathrm{rev}$, $300 \mathrm{rpm}$ respectively. The delamination factor was found minimum HSS tool [5]. Similarly, an experimental study is conducted to know the influence of geometry of drill and process parameters on delamination. And it is found that minimum delamination is observed for both HSS and Polycrystalline diamond (PCD) drills with varying speed and constant feed. But while varying speed and feed the minimum delamination is identified only in PCD tool [6]. The effect of process parameters of drilling was considered on agave composite to know the fracture behavior. Here Polyester resin was used as the matrix and the composite was prepared by hand layup method. For agave composites better delamination is identified at low cutting speed and feed rate. And there is a least effect on drill diameter with delamination factor [9]. Similarly effect of drilling-parameters studied on different composites like hemp, glass and sandwich fibres composites were prepared by different fibre volume fractions. And it is observed that the drilling at higher cutting speed and lower feed rates is suitable for machining Fiber Reinforced Polymer (FRP) composites [10]. For the delamination factor of glass epoxy composites, experimental investigation is carried to know the effect of feed, drill point angle, rotation speed. The delamination factor found minimum at 100 $\mathrm{mm} / \mathrm{min}$ feed rate drill bit angle of $90^{\circ}$ and rotational speed of $2000 \mathrm{rpm}$. The thrust force also minimum at same values of drill bit angle and cutting speeds [11]. To optimize the delamination process Taguchi method is introduced to investigate the drilling factor which causes delamination damage on jute reinforced composites while drilling. And also ANOVA analysis was used to found the minimum value of drilling factors to minimize the delamination. From the ANOVA results, the drill bit diameter plays a major influence on delamination. The minimized delamination factor values are obtained at $6 \mathrm{~mm}$ drill size, $50 \mathrm{~mm} / \mathrm{min}$ feed rate and $3000 \mathrm{rpm}$ spindle speed [7]. The influence of spindle speed, drill diameter and feed rate on delamination of sisal/banana reinforced composites was evaluated. On the basis of Taguchi method drilling parameters were considered for conducting experimentation on the sisal/banana reinforced composites. The results showed that with increasing in speed the delamination factor was decreased due to presence of fibre. By ANOVA response table the optimum values of parameters for minimum delamination at speed of $1500 \mathrm{rpm}$, feed of $50 \mathrm{~mm} / \mathrm{min}$ and $6 \mathrm{~mm}$ drill diameter [8]. Similar experimentation is conducted to find the optimum drilling properties (feed, and cutting speed) on delamination factor of hemp polyester composites using ANOVA analysis and Taguchi method. The results show that the two parameters have a major contribution on the delamination factor and tensile strength. Similar examination is done on basalt fiber reinforced composites to find the influence of drill parameters such as speed of spindle, amount of feed and point angle on the delamination factor. The optimum values were found using Taguchi method and ANOVA analysis. The results showed that max cutting speed, minimum feed rate and higher bit angle are suitable for drilling basalt fiber composites and give minimum delamination [13].

In the current study, established experimental information is used to develop RSM method, ANN model to forecast the delamination in JCCJ hybrid composites drilled on geared drilling machine. And also study the effect of weighted filler material on feed rates, drill delamination damage. The process parameters considered in this work are cutting speed, feed, filler weightage in composite and diameter of drill bit. RSM and ANN models are designed to optimize the process output.

\section{MATERIALS AND METHODS}

\subsection{Specimen's preparation and drilling}

The composites required for drilling were fabricated using woven fabric (WFC200) carbon fiber and jute with epoxy (matrix) using hand layup technique. The piling order of the laminates is Jute- Carbon-CarbonJute with angle of $0^{\circ}$ and $90^{\circ}$ alternatively( J-C-C-J [0/90)] [13]. The Jute-Carbon fiber reinforced polymer laminates were prepared with a dimension of $100 \times 100 \times 15 \mathrm{~mm}$. And uniform volume fraction is considered by mixing Nano fly-ash filler material in terms of $1 \mathrm{~g}, 3 \mathrm{~g}$, and $5 \mathrm{~g}$. The prepared samples with varying filler material are shown in Figure 1. The experiments were repeated three times, and the average value is shown. The percentage of error in the conducted experiments was found to be within $1 \%$ of what the literature recommends. The experimentation was carried out on geared vertical drilling machine having speed range from $75 \mathrm{rpm}$ to $2070 \mathrm{rpm}$ resp. The Figure 2 shows about drilling on prepared composite by varying the process parameters like drill diameter from $6 \mathrm{~mm}$ to $11 \mathrm{~mm}$, feed from 0.06 to $0.1 \mathrm{~mm} / \mathrm{rev}$, speed $275 \mathrm{rpm}$ to $875 \mathrm{rpm}$. Based on the literature, the selected parameters range is considered [14]. Figure 3 show that different sizes holes drilled on composite by varying the input parameters. And also it shows the measurement of drill periphery.

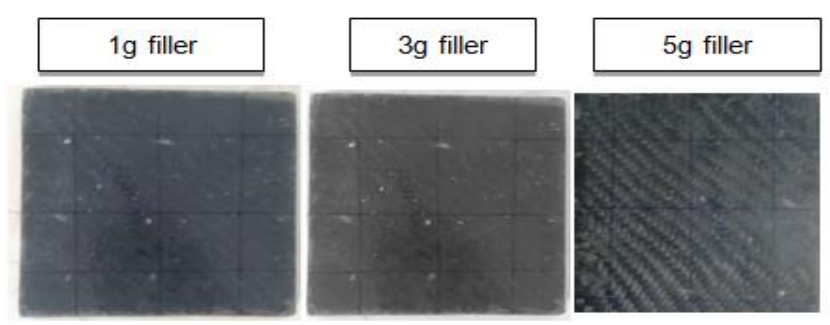

Fig. 1. JCCJ+ different $\%$ of filler added composite 
Due to the high utilization of composites in varied range of performance structures, it is necessary to study the Failure analysis in laminated composite materials. Delamination is one of the fracture studies which play a key role on drilling operation on composite materials.

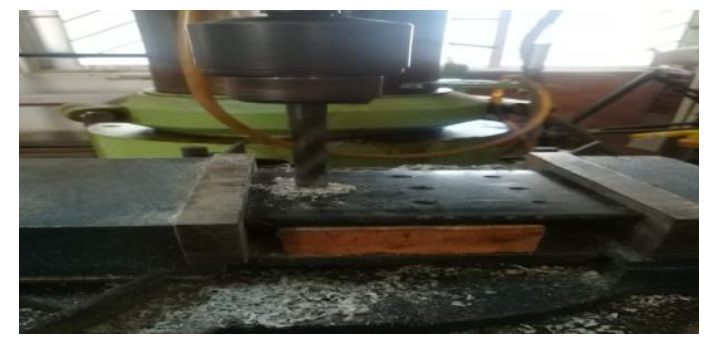

Fig. 2. Drilling on composite

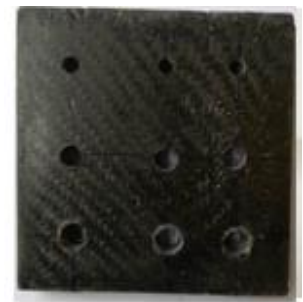

Fig. 3. Holes obtained on specimen

Delamination is the parting of two neighboring laminate surfaces in composite represents serious failure modes in composites. It is necessary for finding the life of composite laminates by finding the inter laminate shear strength. This strength increase by restrict the crack propagation and its damage tolerance [19]. So the crack propagation is observed by the delamination damage. The maximum width of the damage around the slot is found using profile projector shown in Figure 4. Delamination damage factor $\left(F_{d}\right)$ can be calculated using the below equation (1):

$$
\mathrm{Fd}=\mathrm{Wmax} / \mathrm{W}
$$

\section{Where:}

Wmax = Maximum width of the damage around the slot peripher in $\mathrm{mm}$

$\mathrm{W}=$ Width of cut in $\mathrm{mm}$

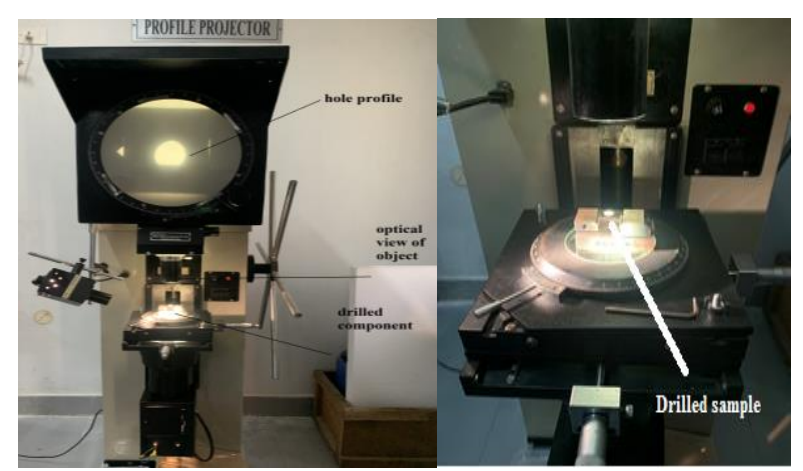

Fig. 4. Profile projector for measuring maximum width

\section{DESIGN OF EXPERIMENTS}

To optimize the experimental results two methods were considered in this experimentation: Response Surface Methodology and Artificial Neural Network Model.

By using these optimization techniques the optimized parameters were identified.

\subsection{Response Surface Methodology (RSM)}

The current work describes the results obtained in case of experimental plan with 4 factor and 3 levels for each of its response parameters.

The selected experimental data is analysed at three separate equal ranges of intervals in a three-level BoxBehnken Design.for performing regression study the design of experiments are designed in Minitab software.

Table 1. Levels of Coded and real values

\begin{tabular}{|c|c|c|c|}
\hline \multicolumn{3}{|l|}{ Level of coded variables } & variables \\
\hline-1 & 0 & 1 & \\
\hline 1 & 3 & 5 & Filler(g) \\
\hline 6 & 8.5 & 11 & Diameter(mm) \\
\hline 0.06 & 0.08 & 0.1 & Feed(mm/rev) \\
\hline 275 & 440 & 875 & Speed(rpm) \\
\hline
\end{tabular}

The coded values and real values of variable parameters used in Box-Behnken design (BBD) is presented in Table 1. The experimental data using BBD technique is analyzed and the expression for quadratic model is shown in equation (2).

$$
F_{d}=\beta_{0}+\sum_{i=1}^{k} \beta_{i} x_{i}+\sum_{i=1}^{k} \beta_{i i} x_{i}^{2}+\sum_{i=1} \sum_{j=i+1} \beta_{i j} x_{i} x_{j}+\varepsilon
$$

where: $F_{d}=$ response $(F A M E), \beta_{0}=$ constant; $\beta_{i}=$ linear coefficient, $\beta_{\mathrm{ii}}=$ quadratic coefficient; $\beta_{\mathrm{ij}}=$ interaction coefficient effects; $\mathrm{x}_{\mathrm{i}}, \mathrm{x}_{\mathrm{j}}=$ independent factors variables and $\varepsilon=$ error or rezidue.

The experimental information shown in the present process is finished and average and duplicate values were exhibited for achieving superior accuracy.

\subsection{Artificial Neural Network Model (ANN)}

In neural network model the information used for training (input and target) is normalized in between the bounds -1 to +1 . This normalized information is Tansig (Tangent sigmoid) function used for ANN and it is also ranges in between -1 and +1 . Normalization is done by using the training information is represented in the equation (3).

$$
\text { Normalized equation }=\left[\frac{\left(2 X_{\mathrm{AC}}-2 \mathrm{X}_{\min }\right)}{\mathrm{X}_{\max }-\mathrm{X}_{\min }}\right]
$$

where $X_{A c}, X_{\min }$, and $X_{\max }$ are the actual, least, highest data, respectively. 
For this study the two layered feed-forward neural network algorithm is used which is having the two transfer functions Tansig, purelin. Here, MATLAB "Neural network Tool box" software, is considered for predicting the delamination factor shown in Figure 5. High $\mathrm{R}^{2}$ coefficient and low mean square error values were considered as the criteria for selection for best results using ANN. And the selection of optimum neutrons based on trial runs are provided on Table 2.

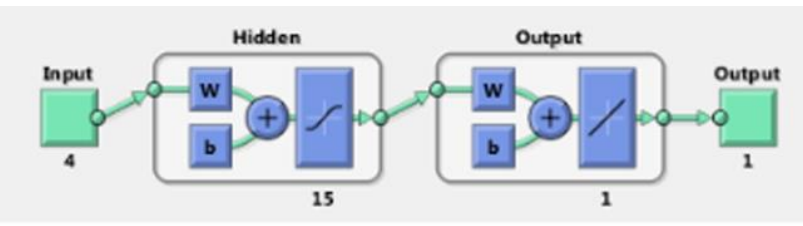

Fig. 5 Levenberg-Marquardt feed-forward back propagation

Table 2. Trail run values to find optimum neutrons

\begin{tabular}{|c|c|c|c|}
\hline $\begin{array}{c}\text { Hidden } \\
\text { Neutrons }\end{array}$ & Training & $\begin{array}{c}\text { validati } \\
\text { on }\end{array}$ & Test \\
\hline 5 & 0.98423 & 0.8756 & 0.8598 \\
\hline 10 & 0.9468 & 0.8544 & 0.8464 \\
\hline 15 & 0.99955 & 0.92571 & 0.95284 \\
\hline 20 & 0.9242 & 0.8468 & 0.8842 \\
\hline
\end{tabular}

\subsection{Model comparison}

To compare the developed models of RSM and ANN, the hierarchical cluster analysis was employed. The visual representation of comparison is depicted using dendrogram of hierarchical cluster analysis using the Euclidean distance as the measure of distance and complete linkage strategy to link clusters with in the data.

\section{RESULTS AND DISCUSSION}

\subsection{RSM predictive model}

The experimental results obtained are optimized by

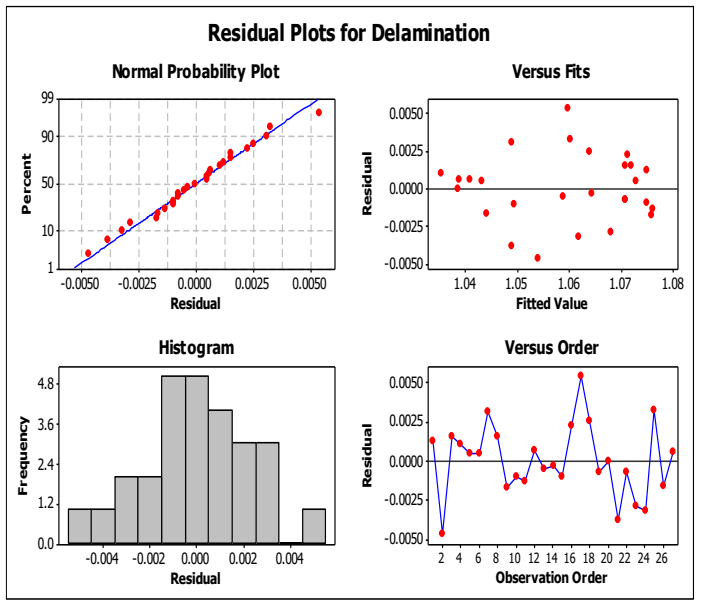

(a)

Fig. 6. Residual plots for delamination using both RSM model and ANN model, the results and residual deviation is shown in Table 4. By using the obtained results, a regression equation of 2 nd order polynomial is established by using chosen coded units.

By using the coded units the final delamination equation represented in equation (4).

$$
\begin{aligned}
F_{d}= & 1.07-0.005 A-0.00186 B+0.00039 C-0.0059 D- \\
& 0.02189 A^{2}-0.00048 B^{2}+0.00317 C^{2}-0.00602 D^{2} \\
& -0.00350 A B-0.00352 A C+0.00418 A D-0.00003 B C \\
& -0.00765 B D+0.00138 C D
\end{aligned}
$$

Where $\mathrm{A}=$ Filler $(\mathrm{g})$ : $\mathrm{B}=$ diameter $(\mathrm{mm})$ : $\mathrm{C}=$ Feed $(\mathrm{mm} / \mathrm{rev}): \mathrm{D}=$ speed $(\mathrm{rpm})$

Analysis of variance (ANOVA) is used to understand the significance of each coefficient. Regression model is efficient at $95 \%$ confidence level. In the above design the obtained $\mathrm{R}^{2}$ value is $97.16 \%$. So it is a signal that the model is a good fit. And furtherly it is found that the spindle speed is the high influence factor $(47.82 \%)$ after that filler is the most influence factor (47.25) followed by drill diameter $(4.96 \%)$. From the analysis it is also identified that the established model is significant and the defined Pvalue is shown in Table 3. For the developed model the standard deviation found to be 0.00336375 . From the entire analysis there is a good similarity between experimental data to the predicted data of RSM which is indicated through normal probability graph in Figure 6. From the residuals vs fits graph in Figure 6 it is observed that the fitted data lies from -0.0050 to 0.0050 having a constant variance and from histogram it is identified that from -0.004to 0.002 the reliably shows skewness then up to 0.04 the reliably shows an outlier. The final graph in Figure 6 it is also observed that it is a cyclic process.

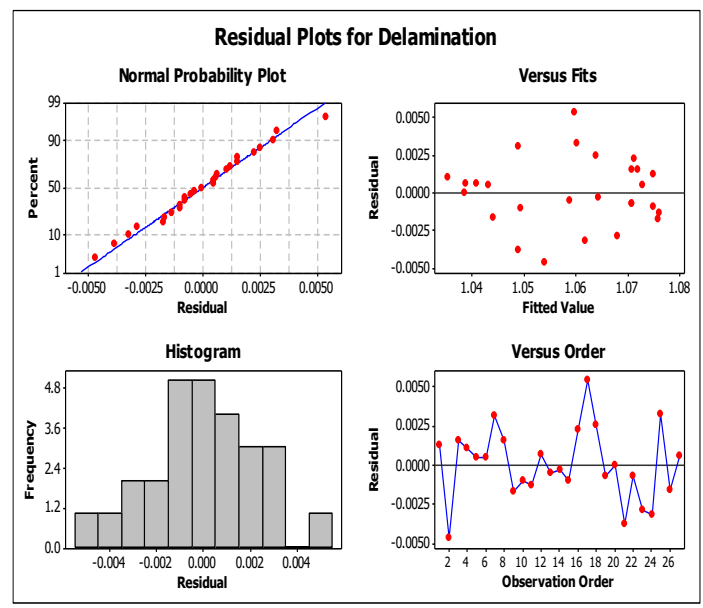

(b) 
Table 3. ANOVA for composite delamination

\begin{tabular}{|c|l|l|l|l|l|}
\hline Source & DOF & SS & MS & F-value & P-value \\
\hline Regression & 14 & 0.004642 & 0.000332 & 29.30 & 0.000 \\
\hline Linear & 4 & 0.000874 & 0.000219 & 19.31 & 0.000 \\
\hline Filler & 1 & 0.000413 & 0.000413 & 36.50 & 0.000 \\
\hline Dia & 1 & 0.000041 & 0.000041 & 3.66 & 0.080 \\
\hline Feed & 1 & 0.000002 & 0.000002 & 0.16 & 0.694 \\
\hline Speed & 1 & 0.000418 & 0.000418 & 36.92 & 0.000 \\
\hline Square & 4 & 0.003358 & 0.000839 & 74.19 & 0.000 \\
\hline Filler*Filler & 1 & 0.003004 & 0.002556 & 225.90 & 0.000 \\
\hline Dia*Dia & 1 & 0.000000 & 0.000001 & 0.11 & 0.748 \\
\hline Feed*Feed & 1 & 0.000161 & 0.000054 & 4.74 & 0.050 \\
\hline Speed*Speed & 1 & 0.000193 & 0.000193 & 17.06 & 0.001 \\
\hline Interaction & 6 & 0.000410 & 0.000068 & 6.04 & 0.67 \\
\hline Filler*Dia & 1 & 0.000049 & 0.000049 & 4.33 & 0.060 \\
\hline Filler*Feed & 1 & 0.000050 & 0.000050 & 4.39 & 0.058 \\
\hline Filler*Speed & 1 & 0.000070 & 0.000070 & 6.16 & 0.029 \\
\hline Dia*Feed & 1 & 0.000000 & 0.000000 & 0.00 & 0.988 \\
\hline Dia*Speed & 1 & 0.000234 & 0.000234 & 20.69 & 0.001 \\
\hline Feed*Speed & 1 & 0.000008 & 0.000008 & 0.67 & 0.430 \\
\hline Residual Error & 12 & 0.000136 & 0.000011 & & \\
\hline Lack-of-Fit & 10 & 0.000132 & 0.000013 & 7.50 & 0.123 \\
\hline Pure Error & 2 & 0.000004 & 0.000002 & & \\
\hline Total & 26 & 0.004778 & & & \\
\hline
\end{tabular}

Table 4. BBD of process variables with predicted and experimental response

\begin{tabular}{|c|c|c|c|c|c|c|c|c|c|}
\hline \multirow[t]{2}{*}{ Run } & \multirow{2}{*}{$\begin{array}{c}\text { A } \\
\begin{array}{c}\text { Filler } \\
(\mathrm{g})\end{array} \\
\end{array}$} & \multirow{2}{*}{$\begin{array}{c}\text { B } \\
\begin{array}{c}\text { Diameter } \\
(\mathbf{m m})\end{array}\end{array}$} & \multirow{2}{*}{$\begin{array}{c}\text { C } \\
\begin{array}{c}\text { Feed } \\
(\mathrm{mm} / \mathrm{rev})\end{array}\end{array}$} & \multirow{2}{*}{$\begin{array}{c}\text { D } \\
\text { Speed } \\
(\mathbf{r p m})\end{array}$} & \multicolumn{3}{|c|}{ Delamination } & \multicolumn{2}{|c|}{ Residuals } \\
\hline & & & & & $\begin{array}{c}\text { Experim } \\
\text { ental }\end{array}$ & RSM & ANN & RSM & ANN \\
\hline 1 & 3 & 8.5 & 0.06 & 275 & 1.0760 & 1.074804 & 1.074719 & 0.001196 & 0.001281 \\
\hline 2 & 1 & 8.5 & 0.06 & 440 & 1.0493 & 1.053996 & 1.049443 & -0.0047 & -0.00014 \\
\hline 3 & 3 & 11 & 0.1 & 440 & 1.0735 & 1.071967 & 1.074133 & 0.001533 & -0.00063 \\
\hline 4 & 5 & 8.5 & 0.08 & 875 & 1.0363 & 1.035267 & 1.036505 & 0.001033 & -0.00021 \\
\hline 5 & 5 & 8.5 & 0.1 & 440 & 1.0435 & 1.043046 & 1.04346 & 0.000454 & $3.99 \mathrm{E}-05$ \\
\hline 6 & 3 & 8.5 & 0.1 & 275 & 1.0733 & 1.072838 & 1.070517 & 0.000463 & 0.002783 \\
\hline 7 & 1 & 11 & 0.08 & 440 & 1.0520 & 1.048904 & 1.045903 & 0.003096 & 0.006097 \\
\hline 8 & 3 & 8.5 & 0.08 & 440 & 1.0723 & 1.070767 & 1.069492 & 0.001533 & 0.002808 \\
\hline 9 & 3 & 6 & 0.1 & 440 & 1.0740 & 1.075733 & 1.074148 & -0.00173 & -0.00015 \\
\hline 10 & 3 & 6 & 0.06 & 440 & 1.0739 & 1.0749 & 1.073262 & -0.001 & 0.000638 \\
\hline 11 & 3 & 11 & 0.08 & 275 & 1.0746 & 1.075963 & 1.073442 & -0.00136 & 0.001158 \\
\hline 12 & 5 & 6 & 0.08 & 440 & 1.0415 & 1.040888 & 1.04146 & 0.000612 & $4.02 \mathrm{E}-05$ \\
\hline 13 & 1 & 8.5 & 0.08 & 275 & 1.0583 & 1.0588 & 1.061477 & -0.0005 & -0.00318 \\
\hline 14 & 3 & 6 & 0.08 & 275 & 1.0640 & 1.064379 & 1.070397 & -0.00038 & -0.0064 \\
\hline 15 & 5 & 8.5 & 0.06 & 440 & 1.0483 & 1.049313 & 1.048158 & -0.00101 & 0.000142 \\
\hline 16 & 3 & 11 & 0.06 & 440 & 1.0735 & 1.071233 & 1.072945 & 0.002267 & 0.000555 \\
\hline 17 & 1 & 6 & 0.08 & 440 & 1.0650 & 1.059621 & 1.064293 & 0.005379 & 0.000707 \\
\hline 18 & 3 & 8.5 & 0.1 & 875 & 1.0663 & 1.063788 & 1.066365 & 0.002512 & $-6.49 \mathrm{E} 05$ \\
\hline 19 & 3 & 8.5 & 0.08 & 440 & 1.0700 & 1.070767 & 1.069492 & -0.00077 & 0.000508 \\
\hline 20 & 1 & 8.5 & 0.08 & 875 & 1.0386 & 1.03865 & 1.038745 & $-5 \mathrm{E}-05$ & -0.00014 \\
\hline 21 & 3 & 11 & 0.08 & 875 & 1.0450 & 1.048863 & 1.044938 & -0.00386 & $6.21 \mathrm{E}-05$ \\
\hline 22 & 3 & 8.5 & 0.08 & 440 & 1.0700 & 1.070767 & 1.069492 & -0.00077 & 0.000508 \\
\hline 23 & 3 & 6 & 0.08 & 875 & 1.0650 & 1.067879 & 1.065639 & -0.00288 & -0.00064 \\
\hline 24 & 1 & 8.5 & 0.1 & 440 & 1.0586 & 1.061829 & 1.058598 & -0.00323 & $1.69 \mathrm{E}-06$ \\
\hline 25 & 3 & 8.5 & 0.06 & 875 & 1.0635 & 1.060254 & 1.063204 & 0.003246 & 0.000296 \\
\hline 26 & 5 & 11 & 0.08 & 440 & 1.0425 & 1.044171 & 1.0479 & -0.00167 & -0.0054 \\
\hline
\end{tabular}




\subsection{Effect of Input process parameters}

Three dimensional surface plots drawn between process parameters vs delamination as shown in Figure 7.

Figure 7(a) shows the influence of filler material and diameter of drill bit on delamination for the fixed speed 440rpm and feed of 0.08. Figure 7(a) shows that up to 3 grms addition of fly ash filler in composite the delamination is increases from 1.06 to 1.07. This is due to increasing the filler, the bonding nature of the laminates increases which casus more delamination [15,16]. The same observation is identified in the current work. After certain limit the delamination gets decreases due to hybridization and filler that contain more amount of $\mathrm{Al}_{2} \mathrm{O}_{3}$.

Figure 7(a) also shows the variation of delamination with respect to diameter of drill bit. Drill diameter in the most influence factor in drilling operation which casus the more delamination [17]. From Figure 7(a) it is identified that the delamination is slightly varies with change in diameter. This is due to the addition of filler in the composites which reduces the delamination.

Figure 7(b) shows the influence of speed and filler material on delamination for the fixed Feed of $0.08 \mathrm{~mm} / \mathrm{rev}$ and diameter $8 \mathrm{~mm}$. Although drill speed is one of the influence factor on delamination. High speed conditions delamination $g$ ets decreases [18] from Figure 7(b) it is observed that the slight increase in delamination this is due to addition of filler which causes more bonding between laminates. So it requires a little high force to drill. So it causes the increases in delamination later its get decreases.

Figure 7(c) shows the influence of filler material and feed on delamination for the fixed speed of 450rpm and diameter $8 \mathrm{~mm}$. Feed is the one of the influence factor on delamination. Increasing feed causes the increase in delamination [17]. Figure 7(c) it is observed that the delamination is constant for increase in feed from min value to maximum value. This is due to addition of filler which can with stand for high feed drilling conditions.

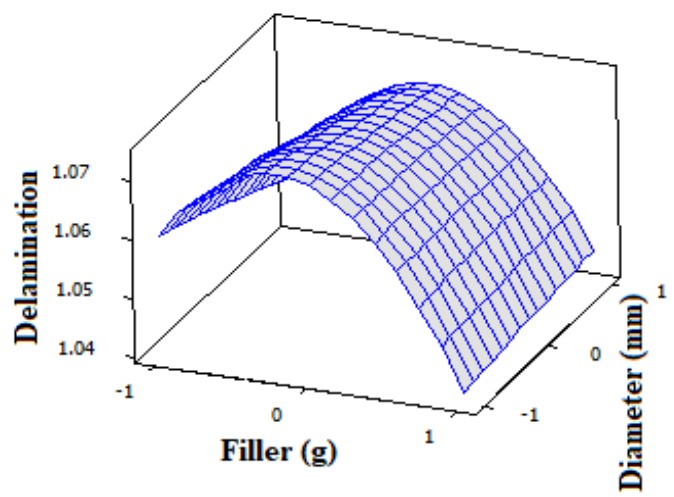

(a)

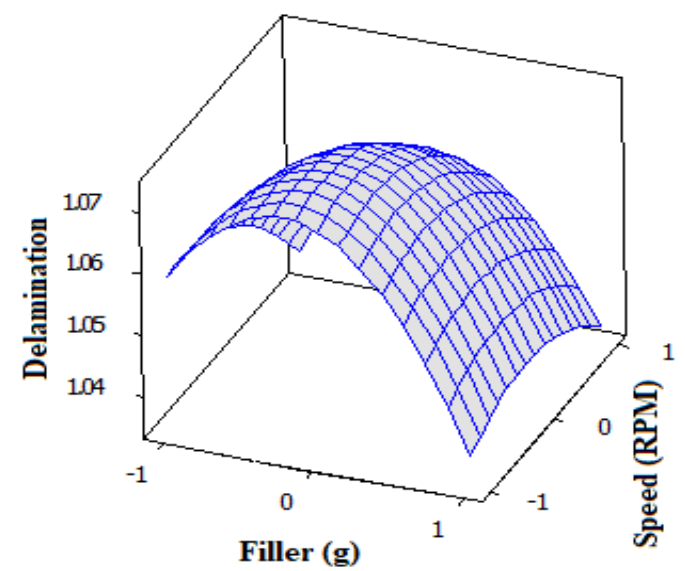

(b)

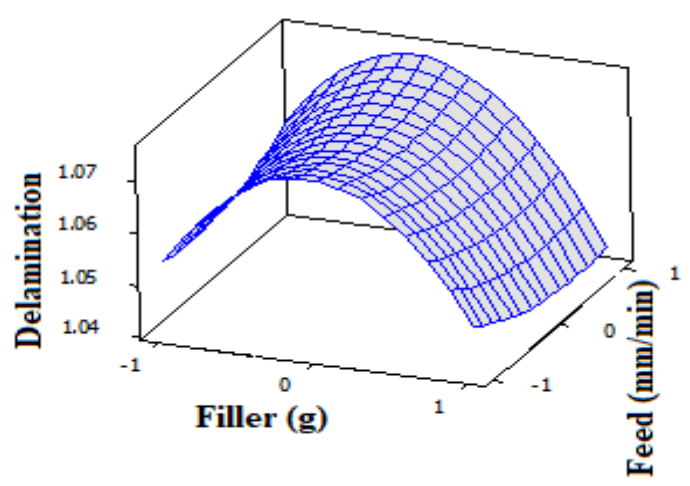

(c)

Fig. 7. Response graphs effect on Delamination (a) Filler and Diameter (b) Filler and Speed (c) Filler and Feed

\subsection{Estimation of Regression Coefficients for Delamination}

From the ANOVA analysis it is clearly identified that the selected process variables in drilling have major influence on delamination ( $\mathrm{P}$-value $<=0.05 ; 97 \%$ confidence level). So the null hypothesis (Ho) stands rejected.

\subsection{ANN based predictive model}

Artificial Neural Network (ANN) models are more efficient than linear regressing models when performing multi variable optimization [18]. In present work the experimental findings were indiscriminately divided into 3-sub division's i.e. testing, training and validation. $70 \%$ of experimentation data was considered for training randomly, $15 \%$ data for validation and $15 \%$ data for testing. Weighted parameters Iterations have been performed un-till low value of mean square error was reached in between predicted delamination and experimental value. The minimum mean square error is found at 0.00021 at 15 epoch, which is near to acceptable limit for MSE to 0.001. In order to achieve the above said point Levenberg-Marquardt feed-forward back propagation is employed with 15 
neurons in hidden layers shown in Figure 5. The optimum network topology of ANN is obtained at 4:15:1 which infers that input layer, hidden layer and output layer have four input variables, fifteen hidden neurons, and single output variable respectively.
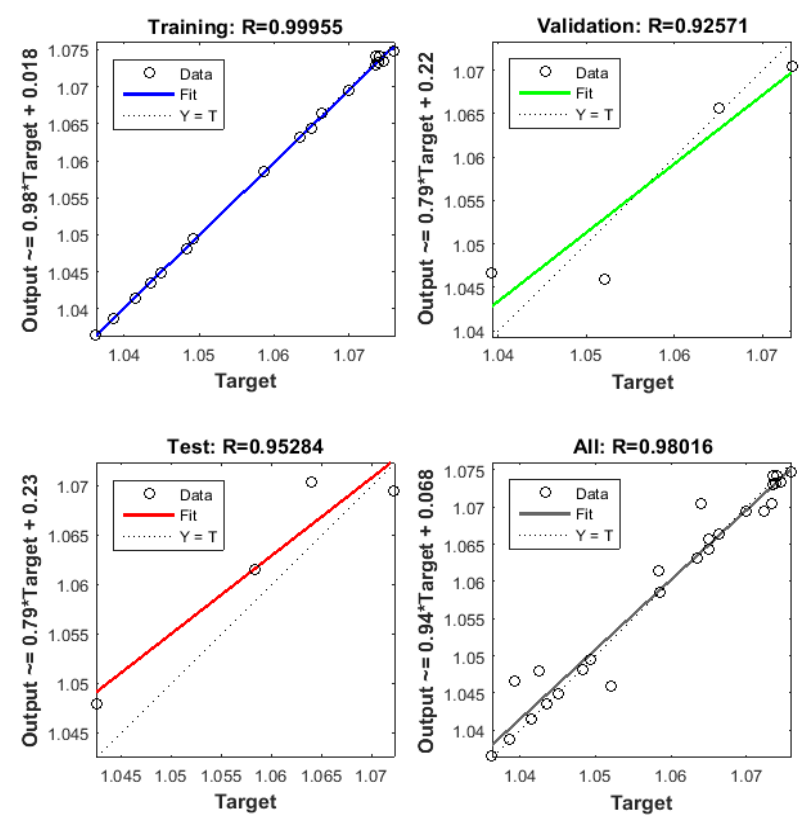

Fig. 8. Experimental Vs Predicted for delamination with ANN model

Tansig, Purelin are the two transfer functions used to model the ANN. The validity of developed ANN model is tested by checking the closeness of $\mathrm{R}^{2}$ values obtained for experimental and predicted responses. $\mathrm{R}^{2}$-values after training, validation, testing, and over-all are $0.9995,0.9257,0.9528$ and 0.98016 respectively are obtained with ANN model is shown in Figure 8. From the obtained $\mathrm{R}^{2}$ values it is indicated that there is an acceptable consistency between the ANN predicted response and experimental response. Therefore, the established model of ANN can exactly predict drilling delamination with superior tractability and have capacity to build relationship with non-linear parameters.

\subsection{Comparison of Predicted models of RSM and ANN}

The ANN and RSM predictive models are compared to check their capability of predicting delamination factor. By using the important parameters like correlation coefficient and root mean square error as a reference the predicted models are compared. The highest value of correlation coefficient for ANN is $\mathrm{R}^{2}=0.99$ and least value of RMSE for ANN is 1.99 and for RSM peak value of coefficient of correlation $\mathrm{R}^{2}=0.97$ and RMSE is 2.24. From the obtained values it is clearly proven that model of ANN is more accurate for delamination prediction when related with RSM model.

\section{MULTIPLE-CORRELATION ANALYSIS}

\subsection{HCA-Hierarchical cluster analysis}

In present work, with the aid of Minitab software perform the Hierarchical cluster analysis using output dataset (delamination) of the experimental, RSM and ANN models. It is executed with single linkage Euclidean distance method and link clusters for standardized variables contained by the dataset. Figure 9 indicates the output data of dendrogram. From dendrogram it is evidently identifies that the output data of experimentation and data predicted with ANN formed a close clusters having similarity-level of 30.03 or distance level of 5.96. Similarly predicated data with RSM model having a similarity-level of 13.60 or distance-level of 7.35 when compared with the experimental output. From HCA it is clearly observed that the output data of experimentation and data predicted with ANN shows a similar in tendency.

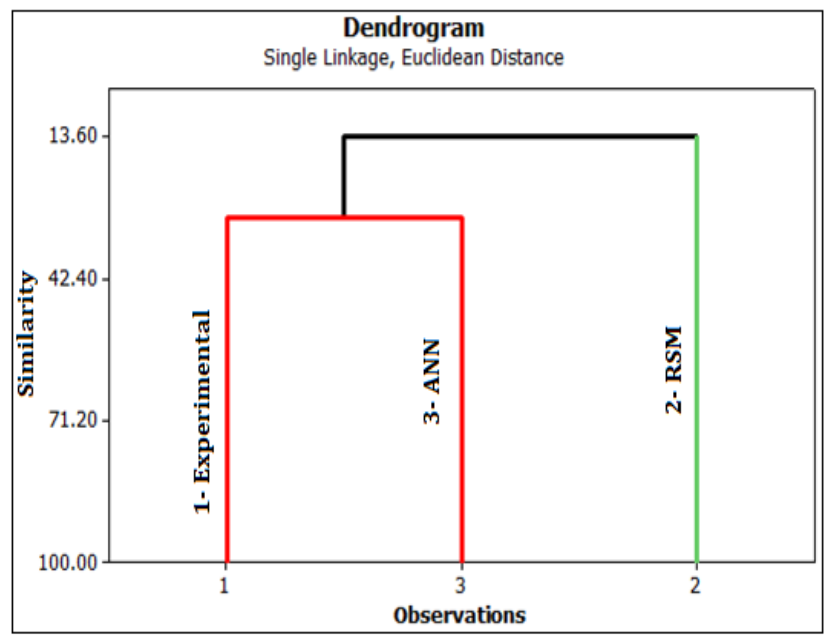

Fig. 9. Dendogram representation of experimental versus predictive models

\section{CONCLUSIONS}

The effect of process parameters of drilling on delamination damage is optimized by using two techniques that is RSM and ANN models. The below observations are found from the experimental results:

With the RSM tool the experiments are modeled and optimized. BY using coded units regression model is established and observed the $\sim 97.16 \%$ drill delamination effect by varying process parameters. And also Artificial neural network model (4:15:1) is developed for more potential and flexible to establish the non-linear relation.

Comparison of RSM and ANN predicted capabilities discloses the correlation-coefficient $\left(\mathrm{R}^{2}\right)$ is 0.99 and RMSE is 1.99 predicted through ANN is better in exact predication of experimental delamination compare to Response surface model $\left(\mathrm{R}^{2}=0.97\right)$ and (RSME=2.24). From HCA it is clearly observed that the output data of experimentation and data predicted 
with ANN shows a similar in tendency.

The investigation on drill properties shown that the drilling on JCCJ hybrid composites with $5 \mathrm{~g}$ of filler addition at $875 \mathrm{rpm}$ with $8.5 \mathrm{~mm}$ drill bit with $0.08 \mathrm{~mm} / \mathrm{rev}$ feed are feasible conditions that cause less delamination factor of 1.036. While drilling the carbon based composites, the filler influence is more on drill properties which achieve high feed and diameter conditions. At these conditions the ca use of damage is less. Mostly in turbine blades design these drill properties can be utilized while made drills on it.

\section{REFERENCES}

1. Palanikumar, K., Srinivasan, T., Rajagopal, K., \& Latha, B., (2016). Thrust force analysis in drilling glass fiberreinforced/polypropylene (GFR/PP) composites, Materials and Manufacturing Processes, 31(5), 581-586.

2. Rajak, D. K., Pagar, D. D., Menezes, P. L., \& Linul, E. (2019). Fiber-reinforced polymer composites: Manufacturing, properties, and applications, Polymers, 11(10), 1667-1675.

3. Ramesh, M., Palanikumar, K., \& Reddy, K. H., (2014, December). Experimental investigation and analysis of machining characteristics in drilling hybrid glass-sisal-jute fiber reinforced polymer composites, In 5th international \& 26th all india manufacturing technology, design and research conference AIMTDR, IIT guwahati, Assam, India.

4. R. Balaji, C. Sivakandhan, P. Munusamy, D. Muthukumar., (2017). Experimental Study of Mechanical Properties and Drilling Properties of Glass Fibre Composite, Journal of Engineering Research and Application, 7(1), 24-30.

5. Sakthivel, M., Vijayakumar, S., \& Prasad, N. K. (2015). Drilling analysis on basalt/sisal reinforced polymer composites using ANOVA and regression model, Applied Mathematical Science, 9(66), 3285-3290.

6. Madhavan, S., \& Prabu, S. B., (2012). "An experimental study of influence of drill geometry on drilling of carbon fibre reinforced plastic composites", International Journal of Engineering Research Development, 3, 36-44.

7. Aravindh, S., \& Umanath, K., (2015). Delamination in drilling of natural fibre reinforced polymer composites produced by compression moulding, In Applied Mechanics and Materials, 766, 796-800.

8. Saravana Kumar, A., Maivizhi Selvi, P., \& Rajeshkumar, L., (2017). Delamination in Drilling of Sisal/Banana Reinforced Composites Produced by Hand Lay-Up Process, In Applied Mechanics and Materials, 867, 29-33.

9. Sasikumar, K. S. K., (2015). Optimization of drilling parameter on delamination based on taguchi method in drilling of natural fiber reinforced (Agave) composite, International Journal of Recent Technology and Engineering, 4, 53-55.

10. Naveen, P. N. E., Yasaswi, M., \& Prasad, R. V., (2012). Experimental investigation of drilling parameters on composite materials, Journal of Mechanical and Civil Engineering, 2, 30-37.

11. Ghasemi, F. A., Hyvadi, A., Payganeh, G., \& Arab, N. B. M., (2011). Effects of drilling parameters on delamination of glass-epoxy composites, Australian Journal of Basic and Applied Sciences, 5(12), 1433-1440.

12.Babu, G. D., Babu, K. S., \& Gowd, B., (2013). Optimization of machining parameters in drilling hemp fiber reinforced composites to maximize the tensile strength using design experiments, Indian journal of engineering and materials science, 20(5), 385-390.

13. Amuthakkannan, P., Manikandan, V., \& Uthayakumar, M., (2015). Analysis of delamination in drilling of basalt fiber reinforced polymer composites, Materials Physics and Mechanics, 24(1), 1-8.

14.Mohan, N. S., Ramachandra, A., \& Kulkarni, S. M., (2005). Influence of process parameters on cutting force and torque during drilling of glass-fiber polyester reinforced composites, Composite structures, 71(3), 407-413.

15.Kumar, S., Chauhan, S. R., Rakesh, P. K., Singh, I., \& Davim, J. P., (2012). Drilling of glass fiber/vinyl ester composites with fillers, Materials and Manufacturing Processes, 27(3), 314-319.

16. Murugesh, M. C., \& Sadashivappa, K., (2012). Influence of filler material on Glass fiber/epoxy composite laminates during drilling, International Journal of Advances in Engineering \& Technology, 3(1), 233.

17.Tsao, C. C., \& Hocheng, H., (2004). Taguchi analysis of delamination associated with various drill bits in drilling of composite material, International Journal of Machine Tools and Manufacture, 44(10), 1085-1090.

18. Srinivasan, T., Palanikumar, K., \& Rajagopal, K., (2014). Influence of thrust force in drilling of glass fiber reinforced polycarbonate (GFR/PC) thermoplastic matrix composites using box-Behnken design, Procedia Materials Science, 5, 2152-2158.

19.Zareei, N., Geranmayeh, A., \& Eslami-Farsani, R. (2019). Interlaminar shear strength and tensile properties of environmentally-friendly fiber metal laminates reinforced by hybrid basalt and jute fibers. Polymer Testing, 75, 205-212.

Received: August 16, 2021 / Accepted: December 15, 2021 / Paper available online: December 20, 2021 (C) International Journal of Modern Manufacturing Technologies. 